\title{
Oil spill simulation in the Japan Sea
}

\author{
H. Kawamura ${ }^{1}$, T. Kobayashi ${ }^{1}$, N. Hirose ${ }^{2}$, T. Ito ${ }^{1} \&$ O. Togawa ${ }^{1}$ \\ ${ }^{1}$ Research Group for Environmental Science, \\ Division of Environment and Radiation Sciences, \\ Japan Atomic Energy Agency, Japan \\ ${ }^{2}$ Dynamics Simulation Research Center, \\ Research Institute for Applied Mechanics, Kyushu University, Japan
}

\begin{abstract}
An assessment system of the marine environment in the Japan Sea is being developed at the Japan Atomic Energy Agency. This study aims to confirm the validity of the assessment system by reproducing the oil spill at the incident of Russian tanker Nakhodka in January 1997. As a main subject, one of the data assimilation techniques, an approximate Kalman filter, was applied to the assessment system by combining an ocean general circulation model with sea level measurements of satellite data. Using calculated ocean currents, simulations of the behaviour of spilled oil were performed with a particle random-walk model. A number of experiments with different parameters and situations showed that the assimilated daily ocean currents with wind drift were for the simulation for movement of spilled oil.

Keywords: assessment system of marine environment, data assimilation, oil spill, ocean general circulation model, particle random-walk model.
\end{abstract}

\section{Introduction}

The Japan Sea is a marginal sea located in the western part of the North Pacific connecting to open oceans through shallow straits (Tsushima, Tsugaru, Soya and Mamiya Straits). From the point of view of human activities, it is a busy route for international shipments and there are many nuclear-powered facilities in coastal areas of the Japan Sea. Therefore, it is possible that pollutants leak into the Japan Sea at incidents of ships or surrounding facilities.

Taking these situations into account, an assessment system of marine environment in the Japan Sea is expected to develop for forecasting/hindcasting 
a fate of pollutants. An assessment system of marine environment at the Japan Atomic Energy Agency (JAEA) is composed of three main components, an ocean general circulation model, a particle random-walk model and a radiation dose assessment model. The descriptions of an ocean general circulation model and a particle random-walk model are given below.

The purpose of this study is to verify a performance of the assessment system by the oil spill experiment at the incident of Russian tanker Nakhodka taken place in January 1997. The effect of data assimilation technique on reproduction of movement of spilled oil is specifically focused in this study.

\section{Model description}

\subsection{Ocean general circulation model}

RIAMOM (Research Institute for Applied Mechanics Ocean Model) originally developed at RIAM of Kyushu University by Lee [1] and implemented mainly in the Japan Sea with some modifications (Lee et al. [2]) is introduced to the assessment system of marine environment at JAEA.

RIAMOM solves three-dimensional, non-linear, primitive external and internal mode equations on the Arakawa B-grid system in a spherical coordinate with hydrostatic assumption and Boussinesq approximation. It is equipped with some features of numerical schemes such as a potential energy and enstrophyconserving advection scheme (Mesinger and Arakawa [3]) and a slant advection

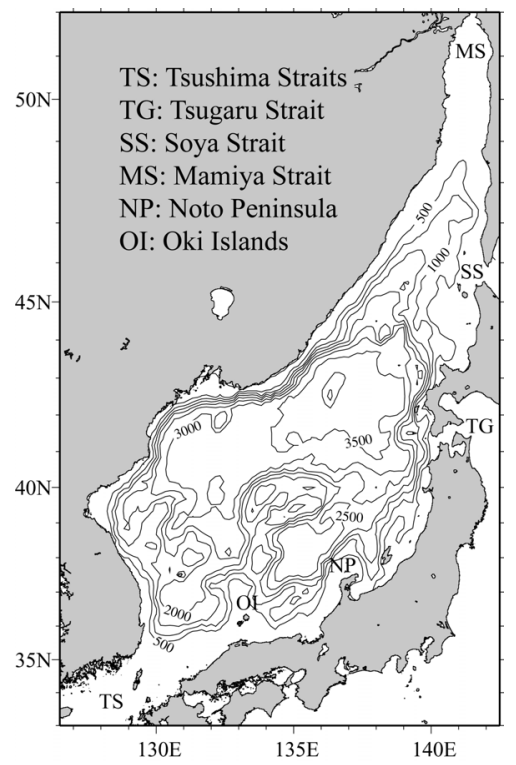

Figure 1: Bottom topography in the Japan Sea. Contour interval is $500 \mathrm{~m}$. 
effect at topographic steps. Time integration is carried out using the leapfrog scheme with the Asselin time filter (Asselin [4]).

The model domain extends from $33^{\circ} \mathrm{N}$ to $52^{\circ} \mathrm{N}$ in latitude and from $126.5^{\circ} \mathrm{E}$ to $142.5^{\circ} \mathrm{E}$ in longitude, which covers an entire Japan Sea (Figure 1). The model has two inflow regions at the eastern/western channel of the Tsushima Straits and two outflow regions at the Tsugaru and Soya Strait. The horizontal grid interval is $1 / 12^{\circ}$ in both latitude and longitude. Taking up 36 vertical levels in the deepest part using depth data incorporates realistic bottom topography.

The vertical eddy viscosity and diffusivity coefficient are set to $1.0 \mathrm{~cm}^{2} / \mathrm{s}$ and $0.1 \mathrm{~cm}^{2} / \mathrm{s}$, respectively, and the horizontal eddy viscosity and diffusivity coefficient are set as values of $7.0 \times 10^{17} \mathrm{~cm}^{4} / \mathrm{s}$ and $7.0 \times 10^{16} \mathrm{~cm}^{4} / \mathrm{s}$, respectively. In the calculation of horizontal eddy viscosity and diffusivity, a highly scale selective biharmonic operator is employed (Semtner and Mintz [5]). An enhanced value of vertical eddy diffusivity coefficient is used in a case of convective adjustment.

\subsection{Data assimilation}

The realistic forecast/hindcast system of ocean conditions in the Japan Sea is being developed with RIAMOM and data assimilation technique at JAEA. The data assimilation is essentially a combination of inductive observations and deductive numerical models. A four-dimensional assimilation of sea surface height from satellite altimeter data; TOPEX/POSEIDON (hereafter, T/P), ERS2 and GFO was carried out into RIAMOM with a Kalman filter (Fukumori et al. [6]). As the sea surface topography reflects an integral effect of ocean interior, the data assimilation can be considered to provide solutions of inverse problems.

The Kalman filter approximated by a horizontal coarse grid with interval of $1 / 3^{\circ}$ and a few major vertical dynamic modes was applied to RIAMOM to reduce a computational transaction. A transformation from the coarse grid to the original grid is performed by the objective mapping (Bretherton et al. [7]) as

$$
\mathbf{x}(t)=C_{f c} C_{c c}{ }^{-1} \mathbf{x}^{\prime}(t),
$$

where $\boldsymbol{x}(t)$ and $\boldsymbol{x}^{\prime}(t)$ are the state vector and reduced-state vector, respectively. $C_{f c}$ is the covariance matrix between the coarse variables and the original variables and $C_{c c}$ is the covariance matrix among all pairs of the coarse variables. In details, refer to Hirose et al. [8].

\subsection{Particle random-walk model}

Movement of material in ocean is calculated with a particle random-walk model (SEA-GEARN) developed at JAEA (Kobayashi et al. [9]). In addition to a basic movement due to advection by ocean currents, a particle experiences a random diffusion caused by horizontal and vertical turbulence. As a result, a trajectory of particle with a time interval of $\Delta t$ is represented in sigma coordinate as

$$
\begin{aligned}
& x_{t+1}=x_{t}+u \Delta t+\delta x, \\
& y_{t+1}=y_{t}+v \Delta t+\delta y, \\
& \sigma_{t+1}=\sigma_{t}+w \Delta t+\delta \sigma,
\end{aligned}
$$


where $x, y$ and $\sigma$ are positions of particles and $u, v$ and $w$ are eastward, northward and upward velocities, respectively. The third terms of right-hand side represent diffusions of particles and are rewritten using a uniform random number $(R)$ between -0.5 and 0.5 as follows.

$$
\begin{aligned}
& \delta x=\delta y=\sqrt{24 K_{h} \Delta t} R, \\
& \delta \sigma=\sqrt{24 K_{v} \Delta t} R,
\end{aligned}
$$

where $K_{h}$ and $K_{v}$ are the horizontal and vertical eddy diffusion coefficient set as $1.0 \times 10^{6} \mathrm{~cm}^{2} / \mathrm{s}$ and $0.1 \mathrm{~cm}^{2} / \mathrm{s}$, respectively.

An effect of wind drift in the surface and sub-surface layers is taken into consideration using an empirical relation with sea surface wind. A wind-driven current on the top is calculated to be proportional to a wind speed at $10 \mathrm{~m}$ height. Below the depth of $0.1 \mathrm{~m}$, the current is set as be decreasing exponentially with $e$-folding decay scale of $100 \mathrm{~m}$. The wind-driven current is simplified to have the same direction at all depths below the sea surface in the replacement of the Ekman spiral.

(a)

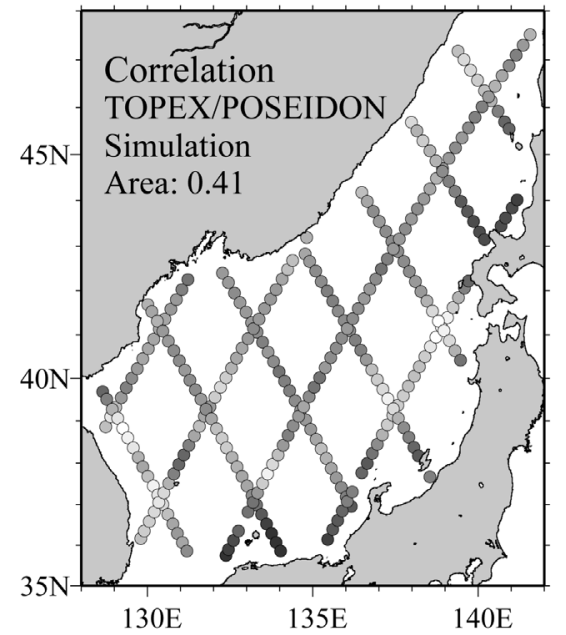

(b)

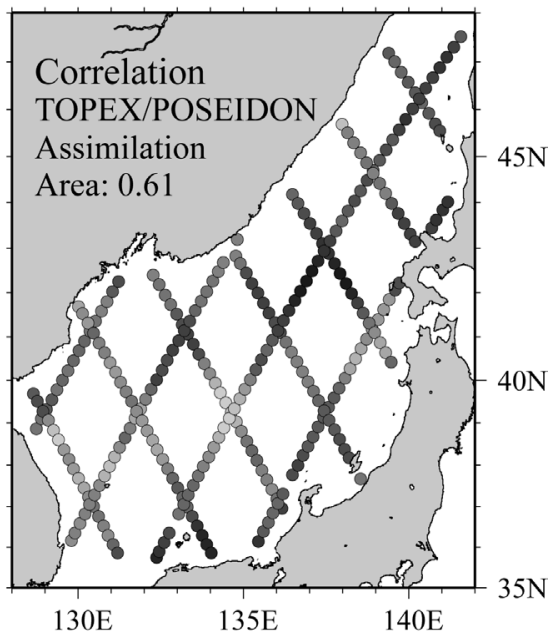

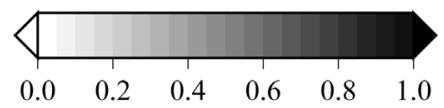

Figure 2: $\quad$ Correlation between T/P altimeter data and (a) simulated and (b) assimilated sea surface height.

\section{Result}

The correlation between model calculations and $\mathrm{T} / \mathrm{P}$ observations averaged temporally from 1996 to 2000 is shown in Figure 2. The averaged correlation over space and time for assimilation was estimated to 0.61 , which is greater than 
that for simulation (0.41). Although a few spatial dependencies of filtered improvement are clear, the assimilated model is expected to be feasible for reproducing the sea level all over the Japan Sea. In addition, the assimilated estimates were validated by higher correlations to the sea surface height observed at coastal stations in Japan. Consequently, the assimilated model is expected to reproduce the realistic ocean phenomena as well as sea surface height, indicating that it is significant for accurate simulation of the movement of spilled oil.

Using the calculated ocean currents, simulations of the behaviour of spilled oil were performed with SEA-GEARN. The tanker was ruptured in a storm about $100 \mathrm{~km}$ north of Oki Islands in Shimane Prefecture, Japan, on January 2, 1997. According to the available visible observed data, most of spilled oil spread over off Hyogo, Kyoto, Fukui and Ishikawa Prefecture, meanwhile a part of it reached the coast of Niigata Prefecture detouring around Noto Peninsula, by January 21, 1997 (Figure 3). Though Varlamov et al. [10] tried to reproduce the movement of spilled oil leaked from the tanker Nakhodka, they failed to simulate the northeastern spread of spilled oil. The most important feature in these regions is considered to be the existence of the Tsushima Warm Current (TWC). Owing to mainly the variability of the TWC, ocean eddy activity and sea surface wind, the spilled oil must be dispersed widely in space from Hyogo to Ishikawa Prefecture. On the other hand, the strong northeastward component of the TWC was likely to drive the spilled oil to the coast of Niigata Prefecture. A number of experiments with different parameters and situations in this study confirmed that the assimilated daily ocean currents with wind drift can reproduce the main features of observed spread of spilled oil after the incident with tanker Nakhodka in the Japan Sea (Figure 3).

(a)

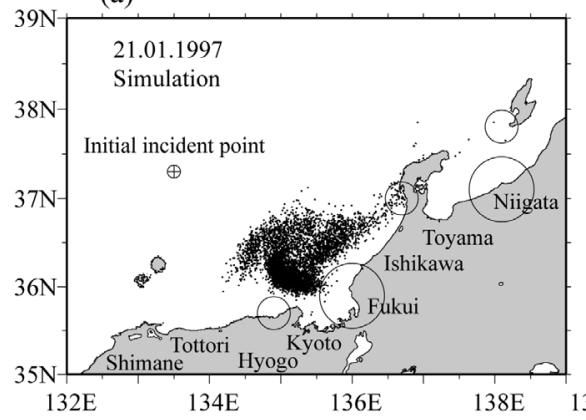

(b)

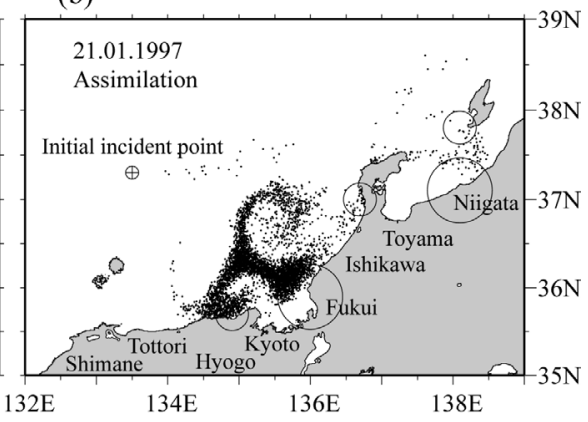

Figure 3: Modelled distributions of spilled oil on January 21, 1997, using (a) simulated and (b) assimilated ocean conditions. Circles mark the observed positions of spilled oil by Japan Coast Guard.

\section{Conclusion}

The assessment system of marine environment in the Japan Sea was demonstrated in the case of incident with tanker Nakhodka. The system consists 
of RIAMOM with an approximate Kalman filter for predicting ocean conditions and SEA-GEARN for dispersion of materials in ocean. The experiments showed that the assimilated daily ocean currents and wind drift effect are valid for the estimate of movement of spilled oil.

In order to predict the trajectory and fate of pollutants at an incident in the Japan Sea, the assessment system of marine environment at JAEA is operationally being developed. To reproduce the structure of currents more accurately, the data assimilation of satellite sea surface temperature is now part of the system.

\section{References}

[1] Lee, H. C., A numerical simulation for the water masses and circulations of the Yellow Sea and the East China Sea. Ph.D. Thesis, Kyushu Univ., pp. $150,1996$.

[2] Lee, H. J., Yoon, J. H., Kawamura, H. \& Kang, H. W., Comparison of RIAMOM and MOM in modelling the East Sea/Japan Sea circulation. Ocean and Polar Res., 25, pp. 287-302, 2003.

[3] Mesinger, F. \& Arakawa, A., Numerical methods used in atmospheric models. GARP Publ. Series, 17, 1, WMO-ICSU Joint Organizing Comm., pp. 64, 1976.

[4] Asselin, R., Frequency filters for time integration. Mon. Weather Rev., 100, pp, 487-490, 1972.

[5] Semtner, J. A. J. \& Mintz, Y., Numerical simulation of the Gulf Stream and mid-ocean eddies. J. Phys. Oceanogr., 7, pp. 208-230, 1977.

[6] Fukumori, I., Raghunath, R., Fu, L. L. \& Chao, Y., Assimilation of TOPEX/Poseidon altimeter data into a global ocean circulation model: How good are the results? J. Geophys. Res., 104, pp. 25647-25665, 1999.

[7] Bretherton, F. P., Davis, R. E. \& Fandry, C. B., A technique for objective analysis and design of oceanographic experiments applied to MODE-73. Deep Sea Res., 23, pp. 559-582, 1976.

[8] Hirose, N., Fukumori, I., Kim, C. H., \& Yoon, J. H., Numerical simulation and satellite altimeter data assimilation of the Japan Sea circulation. Deep Sea Res. II, 52, pp. 1443-1463, 2005.

[9] Kobayashi, T., Lee, S. H. \& Chino, M., Development of ocean pollution prediction system for Shimokita region: Model development and verification. J. Nucl. Sci. and Tech., 39(2), pp. 171-179, 2002.

[10] Varlamov, S. M., Yoon, J. H., Hirose, N., Kawamura, H. \& Shiohara, K., Simulation of the oil spill processes in the Sea of Japan with regional ocean circulation model. J. Mar. Sci. and Tech., 4, pp. 94-107, 1999. 